\title{
Non-Linear Computation of the Equatorial Upwelling*
}

\author{
Koji HIDAKA**
}

\begin{abstract}
The equatorial data of the vertical profile of zonal components of velocity, wind stresses on the surface of the sea, and the slope of isobaric surfaces including the sea surface are used to derive upwelling and sinking, or the vertical components of current at the equator $\left(\varphi=0^{\circ}\right)$. Only thing to be assumed is the coefficient of eddy viscosity. The non-linear hydrodynamical equations were linearized exactly on the Equator by these arrangements to an ordinary differential equations to compute the vertical components of equatorial flow. Numerical result is given.
\end{abstract}

\section{Introduction}

The author has been working theoretically on the explanation of the equatorial current system of the Pacific for several years (HIDAKA, $1962,1963,1965)$ on the assumption that the effects of vertical motion can be disregarded. However, the equatorial regions of the oceans have been frequently watched with keen interest by theoretical oceanographers as the sites of intense upwelling. Moreover, it was pointed out the the field accelerations play an important rôle at the Equator where the Coriolis force vanishes. (ARTHUR, 1960)

Thus the author now intends to explain the equatorial upwelling of the Pacific, making use of the geopotential distances, vertical distribution of zonal component of equatorial flow (Equatorial Undercurrent) determined by direct measurements, the components of wind stresses on the sea surface and the effects of Coriolis force and vertical eddy viscosity, and taking into account the non-linear terms due to field accelerations Thermodynamic processes and effect of horizontal mixing are disregarded.

\section{Hydrodynamical equations at the Equator}

We suppose a meridional section passing through the equator. Take $x-, y-, z$-axes positive eastward, northward and downward and let the velocity components in these directions be $u, v$ and $w$ respectively. Further assume that the east-west variation of velocity

\footnotetext{
* Received May 13, 1966

** Ocean Research Institute, University of Tokyo
}

components is small compared with that in the meridional and vertical directions.

This condition is not necessarily statisfied all the way along the equator. The following discussion therefore applies in some longitudes were this assumption is approximately valid.

For this reason and to make the problem simple, terms

$$
u \frac{\partial u}{\partial x}, \quad u \frac{\partial v}{\partial x}, \quad \text { etc. }
$$

are neglected, except for the east-west pressure gradient:

$$
-\frac{1}{\rho} \frac{\partial p}{\partial x} \text { or }-\frac{\partial D}{\partial x},
$$

which is approximately uniform all the way along the equator. Under these assumptions the steady state hydrodynamical equations for a planetary flow will be, taking into account* the Coriolis component due to vertical velocity component $w$,

$$
\begin{gathered}
\frac{\mu}{\rho} \frac{\partial^{2} u}{\partial z^{2}}-v \frac{\partial u}{\partial y}-w \frac{\partial u}{\partial z}+2 \omega \sin \varphi v \\
+2 \omega \cos \varphi w-\frac{\partial D}{\partial x}=0 \\
\frac{\mu}{\rho} \frac{\partial^{2} v}{\partial z^{2}}-v \frac{\partial v}{\partial y}-w \frac{\partial v}{\partial z}-2 \omega \sin \varphi u \\
-\frac{\partial D}{\partial y}=0
\end{gathered}
$$

while the equation of continuity is

* Suggested by Dr. Takashi ICHIYE, the Lamont Geological Observatory, Columbia University. However, this consideration does not give any significant contribution in the result. 


$$
\frac{\partial v}{\partial y}+\frac{\partial w}{\partial z}=0
$$

where $D$ is the geopotential distance of an isobaric surface counted upward from a sufficiently deep reference level where the motion of water can be neglected, $\omega$ the angular velocity of the Earth, $\varphi$ the geographic latitude, $\rho$ the density of sea water, while $\mu$ is the coefficient of vertical eddy viscosity supposed uniform.

The problem now is how to solve the equations (1) and (2) subject the boundary conditions:

and

$$
z=0:-\frac{\partial u}{\partial z}=\tau_{x} ;-\mu \frac{\partial v}{\partial z}=\tau_{y}
$$

$$
z=h: u=v=0
$$

where $h$ is the depth of the reference level.

It is difficult to say down to what depth the vertical velocity $w$ will exist. It will not vanish at the surface as long as there are slope on, or evaporation from the sea surface. Nevertheless, we assume

$$
z=0 \text { and } z=h: w=0
$$

to the first approximation, because we cannot expect perceptible upwelling or sinking at the sea surface and at the reference level supposed sufficiently deep.

If we eliminate $\frac{\partial v}{\partial y}$ between the equation of continuity (2) and the second equation of (1), we have

$$
\frac{\mu}{\rho} \frac{\partial^{2} v}{\partial z^{2}}-w \frac{\partial v}{\partial z}+\frac{\partial w}{\partial z} v-2 \omega \sin \varphi u-\frac{\partial D}{\partial y}=0
$$

were $\frac{\partial D}{\partial y}$ can be computed from observations.

As is seen from most observations of Equatorial Undercurrent, the distribution of $u$ is very exactly symmetric about the Equator. This observational fact favors us another condition:

$$
\varphi=0: \quad \frac{\partial u}{\partial y}=0 .
$$

Thus (1) becomes

and

$$
\frac{\mu}{\rho} \frac{d^{2} u_{0}}{d z^{2}}-w_{0} \frac{d u_{0}}{d z}+2 \omega w_{0}-\frac{\partial D_{0}}{\partial x}=0
$$

$$
\frac{\mu}{\rho} \frac{d^{2} v_{0}}{d z^{2}}-w_{0} \frac{d v_{0}}{d z}+\frac{d w_{0}}{d z} v_{0}-\frac{\partial D_{0}}{\partial y}=0
$$

where the suffix 0 means that all quantities hereafter refer to the Equator $\left(\varphi=0^{\circ}\right)$. The equation (9) will not be used here in this research. However, it is written down here because it serves to compute $v_{0}$ from $w_{0}$ in later computations.

\section{Computation of vertical component from the profile of zonal component}

There are a number of very detailed measurements of the Equatorial Undercurrent, or the zonal component at the Equator. John A. Knauss combined his own direct measurements into a composite vertical profile. (KNAUSS, 1960, p. 274)

We have from (8),

$$
v_{0}=\frac{\frac{\mu}{\rho} \frac{d^{2} u_{0}}{d z^{2}}-\frac{\partial D_{0}}{\partial x}}{\frac{d u_{0}}{d z}-2 \omega} .
$$

We shall be able to derive the vertical motion $w_{0}$ from this formula by numerical differentiation. This equation will fail at a depth at which $\frac{d u_{0}}{d z}=2 \omega$. This singularity can be avoided by differentiation (8) with respect to $z$, and putting $\frac{d u_{0}}{d z}=2 \omega$, or by using the formula:

$$
w_{0}(z)=\frac{\frac{\mu}{\rho} \frac{d^{2} u_{0}}{d z^{2}}-\frac{\partial^{2} D_{0}}{\partial z \partial x}}{\frac{d^{3} u_{0}}{d z^{3}}}
$$

However, numerical differentiation of higher orders make the result more unreliable due to the accumulation of error of computation. There has been, in addition, a further need of computing the meridional component $v$ from the equation (9). For these reasons, observed vertical distribution of $u_{0}(z)$ and the slope of isobaric surfaces were expanded in series

and

$$
u_{0}(z)=\sum_{n=1}^{\infty} u_{2 n-1} \cdot \cos \frac{(2 n-1) \pi z}{2 h},
$$

$$
\frac{\partial D_{0}}{\partial x} \sum_{n=1}^{\infty}\left(\frac{\partial D}{\partial x}\right)_{2 n-1} \cdot \cos \frac{(2 n-1) \pi z}{2 h},
$$

since both $u_{0}(z)$ and $\frac{\partial D_{0}}{\partial x}$ have to vanish at the reference level $z=h$.

As to the vertical component $\omega_{0}(z)$ which is 
not known as yet, we may assume

$$
\omega_{0}(z)=\sum_{n=1}^{\infty} w_{2 n} \cdot \sin \frac{2 n \pi z}{2 h},
$$

because this component is supposed to vanish both at the sea surface and at the reference level.

Further assume

$$
\begin{aligned}
\frac{d^{2} u_{0}}{d z^{2}}= & \sum_{n=1}^{\infty} \cos \frac{(2 n-1) \pi z}{2 h} \\
& \cdot \frac{2}{h} \int_{0}^{h} \frac{d^{2} u_{0}}{d \xi^{2}} \cos \frac{(2 n-1) \pi \xi}{2 h} d \xi ;
\end{aligned}
$$

then we have by Stokes' method

$$
\begin{aligned}
\frac{2}{\mu} \int_{0}^{h} \frac{d^{2} u_{0}}{d \xi^{2}} & \cos \frac{(2 n-1) \pi \xi}{2 h} d \xi \\
& =\frac{2}{h} \cdot \frac{\tau_{x}}{\mu}-\frac{(2 n-1)^{2} \pi^{2}}{4 h^{2}} u_{2 n-1},
\end{aligned}
$$

where $\tau_{x}$ is the eastward component of wind stress defined by the surface condition (3), or $z=0: \quad-\mu \frac{d u_{0}}{d z}=\tau_{x}$. Thus (15) becomes

$$
\begin{array}{r}
\frac{d^{2} u_{0}}{d z^{2}}=\sum_{n=1}^{\infty}\left\{\frac{2}{h} \frac{\tau_{x}}{\mu}-\frac{(2 n-1)^{2} \pi^{2}}{4 h^{2}} u_{2 n-1}\right\} \\
\cdot \cos \frac{(2 n-1) \pi z}{2 h} .
\end{array}
$$

Integrating both sides of the expression (17) from the surface $z=0$ down to a level $z$, we have, making use of the condition (3),

$$
\begin{aligned}
\frac{d u_{0}}{d z}= & \frac{\tau_{x}}{\mu}+\sum_{n=1}^{\infty}\left\{\frac{2}{h} \frac{\tau_{x}}{\mu}-\frac{(2 n-1)^{2} \pi^{2}}{4 h^{2}} u_{2 n-1}\right\} \\
& \left.\cdot \frac{2 h}{(2 n-1) \pi} \sin \frac{(2 n-1) \pi z}{2 h}\right|_{0} ^{z} \\
= & -\frac{\tau_{x}}{\mu}\left\{1-\frac{2}{h} \sum_{n=1}^{\infty} \frac{2 h}{(2 n-1) \pi} \sin \frac{(2 n-1) \pi z}{2 h}\right. \\
& -\sum_{n=1}^{\infty}\left\{\frac{(2 n-1) \pi}{2 h} u_{2 n-1}\right\} \sin \frac{(2 n-1) \pi z}{2 h},
\end{aligned}
$$

because

But we have

$$
\begin{aligned}
\int_{0}^{z} \frac{d^{2} u_{0}}{d z^{2}} d z & =\frac{d u_{0}}{d z}-\left.\frac{d u_{0}}{d z}\right|_{z=0} \\
& =\frac{d u_{0}}{d z}+\frac{\tau_{x}}{\mu}
\end{aligned}
$$

$$
\frac{2}{h} \sum_{n=1}^{\infty} \frac{2 h}{(2 n-1) \pi} \sin \frac{(2 n-1) \pi z}{2 h}=1,
$$

and the above expression becomes

$$
\frac{d u_{0}}{d z}=\sum_{n=1}^{\infty}\left\{-\frac{(2 n-1) \pi}{2 h} u_{2 n-1}\right\} \sin \frac{(2 n-1) \pi z}{2 h} .
$$

Further, it follows from (18)

$$
2 \omega=2(\omega) \sum_{n=1}^{\infty} \frac{4}{(2 n-1) \pi} \sin \frac{(2 n-1) \pi z}{2 h},
$$

so that we have

$$
\begin{aligned}
&- w_{0}(z) \frac{d u_{0}}{d z}+2 \omega w_{0}(z) \\
&=w_{0}(z) \sum_{n=1}^{\infty}\left\{\frac{(2 n-1) \pi}{2 h} u_{2 n-1}+\frac{4}{(2 n-1) \pi}\right. \\
&\cdot 2(\omega)\} \sin \frac{(2 n-1) \pi z}{2 h} .
\end{aligned}
$$

Substituting from (14), this expression becomes

$$
\begin{aligned}
& \frac{\pi}{4 n} \sum_{n=1}^{\infty}\left[\sum _ { s = 1 } ^ { \infty } \left\{(2 s-2 n+1) u_{2 s-2 n+1}\right.\right. \\
& +\frac{8}{(s-2 n+1) \pi_{2}} \cdot 2 \omega h-(2 s+2 n-1) u_{2 s+2 n-1} \\
& \left.\left.\quad-\frac{8}{(2 s+2 n-1) \pi^{2}} \cdot 2 \omega h\right\} \cdot w_{2 s}\right] \cos \frac{(2 n-1) \pi z}{2 h}
\end{aligned}
$$

Again substituting (13), (17) and (20) in the equation (8), the following expressions are obtained between $w_{2}, w_{4}, \cdots$ and $u_{1}, u_{3}, u_{5}, \cdots$ as follows:

$$
\begin{aligned}
& \sum_{s=1}^{\infty}\{2 s-2 n+1) u_{2 s-2 n+1}+\frac{8}{(2 s-2 n+1) \pi^{2}} \cdot 2 \omega h \\
&+(2 s+2 n-1) u_{2 s+2 n-1} \\
&\left.-\frac{8}{(2 s+2 n-1) \pi^{2}} \cdot 2 \omega h\right\} w_{2 s}+\frac{8}{\pi} \frac{\tau_{x}}{\rho} \\
&-\frac{4 h}{\pi}\left(\frac{\partial D_{0}}{\partial x}\right)_{2 n-1}-\frac{(2 n-1)^{2} \pi}{h}-\frac{\mu}{\rho} u_{2 n-1}=0 \\
&(n, s=1,2,3, \cdots)
\end{aligned}
$$

provided $u_{-j}=u_{j}$ where $j$ is an odd positive integer. These are necessary conditions for the equation (8) to be satisfied, though not sufficient condition.

The solution of the simultaneous equations (22) will give $w_{2}, w_{4}, w_{6}, \cdots$ in terms of $\mu$, $o ; \tau_{x},(\prime)$ and $u_{1}, u_{3}, u_{5}, \cdots ;\left(\frac{\partial D_{0}}{\partial x}\right)_{1},\left(\frac{\partial D_{0}}{\partial x}\right)_{3}$, $\left(\frac{\partial D_{0}}{\partial x}\right)_{5}, \cdots$ determined by harmonic analysis according to the expressions (12) and (13). The vertical velocity component $a_{0}(z)$ will be then given by (14), or

$$
w_{0}(z)=\sum_{n=1}^{\infty} w_{2 n} \sin \frac{2 n \pi z}{2 h}
$$




\section{Numerical computation}

The zonal velocity of the Equatorial Undercurrent was measured by several scientists since Townsend CROMWEll, R. B. MONTGOMERY and E. D. STROUP first discovered this current in the Pacific in September 1951 (CROMWELL, MONTGOMERY and STROUP, 1954). In 1959, John A. KNAUSS made a composite profile of this current $\left(140^{\circ} \mathrm{E}\right)$ by combining various observations by himself (KNAUSS, 1960). The values of $u_{0}(z)$ was read off from Knauss's diagram (KNAUSS, 1960, p. 274) every $50 \mathrm{~m}$ from the surface down to $1,000 \mathrm{~m}$ level. The result is given in the Table $I$ below. At the same time, the average values of $\frac{\partial D_{0}}{\partial x}$ for the same levels over $1,000 d b$ surface were computed from the observational data occupied by Hawaiian oceanographers in the equatorial waters during the "Hugh M. Smith" cruises of 1950, 1951 and 1952 and other data occupied during the IGY and IGC periods. (average of those from $140^{\circ} \mathrm{E}$ to $160^{\circ} \mathrm{W}$ ) (Mid-Pacific Oceanography I, II, III, and Iv, U. S. Department of the Interior Fish and Wildlife Service, Special Scientific Report-Fisheries No. 54, 131 and 135; IGY Oceanographic Report No. 3, parts IIa.) The values of $\tau_{x}$ were averaged from the Hawaiian observations which are available at a spacing of $1^{\circ}$ of meridional arc.

It should be stressed that the correspondence in the area and time observations between the numerical values of $u_{0}(z), \frac{\partial D_{0}}{\partial x}$ and $\tau_{x}$ is important in this sort of computation in order to explain the actual phenomena. However, the author has to confess that it was not easy to select the data all occupied simultaneously and at the same longitude. It should be merely taken as an example of numerical computation for the availability of the method described. Therefore it should be borne in mind that the result would not necessary be always consistent.

The author hopes that someday he would ba possible to use the data occupied at the same time and at the same longitude, so that he would be able to explain actual phenomena more precisely.

The harmonic analysis of $u_{0}(z)$ and $\frac{\partial D_{0}}{\partial x}$
Table 1. Vertical distribution of $u_{0}$ (observed)

$$
\text { and } \frac{\partial D_{0}}{\partial x}
$$

(computed over $1,000 \mathrm{lb}$ reference level from observations)

\begin{tabular}{|c|c|c|c|}
\hline $\begin{array}{l}\text { depth } z \\
\text { (meters or } \\
\text { decibars }\end{array}$ & $\begin{array}{c}u_{0} \\
\underset{(\mathrm{cm} / \mathrm{sec})}{\text { after Knauss) }}\end{array}$ & \multicolumn{2}{|c|}{$\frac{\partial D_{0}}{\partial x}$} \\
\hline 0 & -30 & \multicolumn{2}{|c|}{$-5.22 \times 10^{-5}$} \\
\hline 50 & 130 & -4.39 & $\prime \prime$ \\
\hline 100 & 150 & -2.99 & $\prime \prime$ \\
\hline 150 & 80 & -1.29 & $\prime \prime$ \\
\hline 200 & 48 & -0.09 & $\prime \prime$ \\
\hline 250 & 30 & -0.36 & $\prime \prime$ \\
\hline 300 & 18 & -0.26 & $\prime \prime$ \\
\hline 350 & 8 & -0.21 & $\prime \prime$ \\
\hline 400 & -3 & -0.16 & $\prime \prime$ \\
\hline 450 & -9 & -0.14 & $\prime \prime$ \\
\hline 500 & -11 & -0.11 & $\prime \prime$ \\
\hline 550 & -12 & -0.11 & $\prime \prime$ \\
\hline 600 & -13 & -0.10 & $\prime \prime$ \\
\hline 650 & -13 & -0.10 & $\prime \prime$ \\
\hline 700 & -14 & -0.10 & $\prime \prime$ \\
\hline 750 & -12 & -0.09 & $\prime \prime$ \\
\hline 800 & -10 & -0.08 & $\prime \prime$ \\
\hline 850 & -9 & -0.06 & $\prime \prime$ \\
\hline 900 & -8 & -0.04 & $\prime \prime$ \\
\hline 950 & -5 & -0.02 & $\prime \prime$ \\
\hline 1,000 & 0 & 0 & \\
\hline
\end{tabular}

according to the series:

$$
u_{0}(z)=\sum_{n=1}^{20} u_{2 n-1} \cdot \cos \frac{(2 n-1) \pi z}{2 h}
$$

and

$$
\frac{\partial D_{0}}{\partial x}=\sum_{n=1}^{20}\left(\frac{\partial D_{0}}{\partial x}\right)_{2 n-1} \cdot \cos \frac{(2 n-1) \pi z}{2 h},
$$

gives the values for $u_{1}, u_{3}, u_{5}, \cdots$ and $\left(\frac{\partial D_{0}}{\partial x}\right)_{1}$, $\left(\frac{\partial D_{0}}{\partial x}\right)_{3}, \cdots$ as compiled in Table 2 .

With these coefficients, two series give exactly the same values for $u_{0}(z)$ and $\frac{\partial D_{0}}{\partial x}$ for the 20 levels compiled in Table 1.

The 20 equations for computing $w_{2}, w_{4}, \cdots$ $w_{40}$ are as follows:

$$
\begin{aligned}
&\left(\bar{u}_{1}+3 \bar{u}_{3}\right) w_{2}+\left(3 \bar{u}_{3}+5 \bar{u}_{5}\right) w_{4}+\left(5 \bar{u}_{5}+7 \bar{u}_{7}\right) w_{6}+\cdots \\
&+\left(39 \bar{u}_{37}+0\right) w_{40} \\
&=-\frac{8}{\pi} \frac{\tau_{x}}{\rho}+\frac{4 h}{\pi}\left(\frac{\partial D_{0}}{\partial x}\right)_{1}+\left(\frac{9 \pi}{h} u_{1}\right) \frac{\mu}{\rho} \\
&\left(-1 \bar{u}_{1}+5 \bar{u}_{5}\right) w_{2}+\left(\bar{u}_{1}+7 \bar{u}_{7}\right) w_{4}+\left(3 \bar{u}_{3}+9 \bar{u}_{9}\right) w_{6}+\cdots \\
& \quad+\left(37 \bar{u}_{37}+0\right) w_{40}
\end{aligned}
$$


Table 2. 20 Coefficients in the Expansions in Terms of $\cos \frac{(2 n-1) \pi z}{\partial n}$ for $u_{0}$ and $\frac{\partial D_{0}}{\partial x}$. $(n=1,2,3, \cdots, 20)$

\begin{tabular}{|c|c|c|c|}
\hline \multirow{2}{*}{$\frac{2 n-1}{1}$} & $\begin{array}{c}u_{2 n-1} \\
(\mathrm{~cm} / \mathrm{sec})\end{array}$ & \multicolumn{2}{|c|}{$\begin{array}{l}\left(\frac{\partial D_{0}}{\partial x}\right)_{2 n-1} \\
\left(\mathrm{~cm} / \mathrm{sec}^{2}\right)\end{array}$} \\
\hline & 37.97145 & $-1.32162>$ & $10^{-5}$ \\
\hline 3 & 44.03876 & -1.02983 & $\prime \prime$ \\
\hline 5 & 18.20369 & -0.87126 & $\prime \prime$ \\
\hline 7 & 6.56432 & -0.65931 & $\prime \prime$ \\
\hline 9 & -1.88448 & -0.48882 & $\prime \prime$ \\
\hline 11 & -5.24597 & -0.34498 & $\prime \prime$ \\
\hline 13 & -8.70113 & -0.22131 & $\prime \prime$ \\
\hline 15 & -10.61137 & -0.13134 & $\prime \prime$ \\
\hline 17 & -13.40103 & -0.06846 & $\prime \prime$ \\
\hline 19 & -13.29632 & -0.02842 & $\prime \prime$ \\
\hline 21 & -12.96634 & -0.00454 & $\prime \prime$ \\
\hline 23 & -12.02045 & 0.00918 & $\prime \prime$ \\
\hline 25 & -10.90045 & 0.01566 & $\prime \prime$ \\
\hline 27 & -10.10755 & 0.01593 & $\prime \prime$ \\
\hline 29 & -8.87627 & 0.01074 & $\prime \prime$ \\
\hline 31 & -7.40474 & 0.00346 & $\prime \prime$ \\
\hline 33 & -6.38032 & -0.00947 & $\prime \prime$ \\
\hline 35 & -5.49087 & -0.02506 & $\prime \prime$ \\
\hline 37 & -4.77900 & -0.03390 & $\prime \prime$ \\
\hline 39 & -4.71103 & -0.03710 & $\prime \prime$ \\
\hline
\end{tabular}

$=-\frac{8}{\pi} \frac{\tau_{x}}{\rho}+\frac{4 h}{\pi}\left(\frac{\partial D_{0}}{\partial x}\right)_{3}+\left(-\frac{25 \pi}{h} u_{3}\right) \frac{\mu}{\rho}$,

$\left(-3 \bar{u}_{3}+7 \bar{u}_{7}\right) w_{2}+\left(-\bar{u}_{1}+9 \bar{u}_{9}\right) w_{4}$

$+\left(\bar{u}_{1}+11 \bar{u}_{11}\right) w_{6}+\cdots+\left(35 \bar{u}_{35}+0\right) w_{49}$

$=-\frac{8}{\pi}-\frac{\tau_{x}}{\rho}+\frac{4 h}{\pi}\left(\frac{\partial D_{0}}{\partial x}\right)_{5}+\left(\frac{49 \pi}{h} u_{5}\right) \frac{\mu}{\rho}$,

$\left(-5 \bar{u}_{5}+9 \bar{u}_{9}\right) w_{2}+\left(-3 \bar{u}_{3}+11 \bar{u}_{11}\right) w_{4}$

$+\left(-\bar{u}_{1}+13 \bar{u}_{13}\right) w_{6}+\cdots+\left(33 \bar{u}_{33}+0\right) w_{40}$

$=-\frac{8}{\pi} \frac{\tau_{x}}{\rho}+\frac{4 h}{\pi}\left(\frac{\partial D_{0}}{\partial x}\right)_{7}+\left(\frac{81 \pi}{h} u_{7}\right) \frac{\mu}{\rho}$,

$\left(-35 \bar{u}_{35}+39 \bar{u}_{39}\right) w_{2}+\left(-33 \bar{u}_{33}+0\right) w_{4}$

$+\left(-31 \bar{u}_{31}+0\right) w_{6}+\cdots+\left(13 \bar{u}_{3}+0\right) w_{40}$

$=-\frac{8}{\pi} \frac{\tau_{x}}{\rho}+\frac{4 h}{\pi}\left(\frac{\partial D_{0}}{\partial x}\right)_{37}+\left(\frac{1369 \pi}{h} u_{37}\right) \frac{\mu}{\rho}$,

$\left(-37 \bar{u}_{37}+0\right) w_{2}+\left(-35 \bar{u}_{35}+0\right) w_{4}$

$+\left(-33 \bar{u}_{33}+0\right) w_{6}+\cdots+\left(u_{1}+0\right) w_{40}$

$=-\frac{8}{\pi} \frac{\tau_{x}}{\rho}+\frac{4 h}{\pi}\left(\frac{\partial D_{0}}{\partial x}\right)_{39}+\left(\frac{1521 \pi}{h} u_{39}\right) \frac{\mu}{\rho}$,

where

$(2 n-1) \bar{u}_{2 n-1}=(2 n-1) u_{2 n-1}+\frac{8}{(3 n-1) \pi^{2}} \cdot 2 \omega h$
For $w_{0}(z)$ the series were also confined to 20 terms, or

$$
w_{0}(z)=\sum_{n=1}^{20} w_{2 n} \cdot \sin \frac{2 n \pi z}{2 h}
$$

from which only $w_{2}, w_{4}, w_{6}, \cdots, w_{40}$ are to be determined. The constants used are

$$
\begin{aligned}
& \frac{\tau_{x}}{\rho}=-1.381 \mathrm{c} . \mathrm{g} . \mathrm{s} \\
& h=1,000 \mathrm{~m}=10^{5} \mathrm{~cm}
\end{aligned}
$$

where $\tau_{x}$ was computed from the same sources as $\frac{\partial D_{0}}{\partial x}$.

The computation gives the values of $w_{2 n}$ always in the form:

$$
w_{2 n}=w_{2 n}^{(\mathrm{I})}+\frac{\mu}{\rho} w_{2 n}^{(\text {II })}
$$

where $w_{2 n}{ }^{(\mathrm{I})}$ and $w_{2 n}{ }^{(\mathrm{II})}$ have all opposite signs and are given as compiled in Table 3 .

Table 3. Values of $w_{2 n}^{(\mathrm{I})}$ and $w_{2 n}^{(\mathrm{II})}$ where

$$
w_{2 n}=w_{2 n}^{(\mathrm{I})}+\frac{\mu}{\rho} w_{2 n}^{(\mathrm{II})} \text {. }
$$

\begin{tabular}{rrr}
\hline $2 n$ & \multicolumn{1}{c}{$w_{2 n}^{(\mathrm{I})}$} & \multicolumn{1}{c}{$w_{2 n}^{(\mathrm{II})}$} \\
\hline 2 & -0.0182521 & 0.001008230 \\
4 & 0.0040192 & -0.000212213 \\
6 & 0.0106797 & -0.000770698 \\
8 & 0.0066470 & -0.000490487 \\
10 & -0.0055932 & 0.000362601 \\
12 & -0.0009663 & 0.000156503 \\
14 & 0.0058515 & -0.000385958 \\
16 & 0.0109251 & -0.000633034 \\
18 & 0.0009974 & -0.000055837 \\
20 & -0.0049822 & 0.000313080 \\
22 & 0.0012172 & -0.000052499 \\
24 & 0.0063975 & -0.000482817 \\
26 & 0.0037582 & -0.000227687 \\
28 & -0.0064666 & 0.000393289 \\
30 & -0.0068338 & 0.000400349 \\
32 & 0.0015132 & -0.000243892 \\
34 & 0.0075428 & -0.000568787 \\
36 & -0.0041715 & 0.000176598 \\
38 & -0.0080682 & 0.000589728 \\
40 & -0.0240596 & 0.001329814 \\
\hline
\end{tabular}

Substituting the numerical values for $w_{2 n}$ thus computed in (13), we have the vertical component as follows:

$$
\begin{aligned}
w_{0}(z)= & \sum_{n=1}^{20} w_{2 n}^{(\mathrm{I})} \sin \frac{2 n \pi z}{2 h} \\
& -\frac{\mu}{\rho} \sum_{n=1}^{20} w_{2 n}{ }^{(\mathrm{II})} \sin \frac{2 n \pi z}{2 h}
\end{aligned}
$$


Table 4. Values of $w_{0}^{(I)}(z)$ and $w_{0}^{(1)}(z)$ where $w_{0}(z)=w_{0}^{(\mathrm{I})}(z)+\frac{\mu}{\rho} w_{0}^{(\mathrm{II})}(z)$.

\begin{tabular}{crr}
\hline $\begin{array}{c}\text { depth } z \\
\text { (in meters) }\end{array}$ & \multicolumn{1}{c}{$\begin{array}{c}w_{0}^{(\mathrm{I})}(z) \\
(\mathrm{cm} / \mathrm{sec})\end{array}$} & \multicolumn{1}{c}{$\begin{array}{c}w_{0}^{(\mathrm{II})}(z) \\
(\mathrm{cm} / \mathrm{sec})\end{array}$} \\
\hline 0 & 0 & 0 \\
50 & 0.0163465 & -0.001268386 \\
100 & 0.0198463 & -0.000977431 \\
150 & -0.0060240 & -0.000080141 \\
200 & -0.0015959 & -0.000026192 \\
250 & 0.0001305 & -0.000271689 \\
300 & 0.0001267 & -0.000106977 \\
350 & -0.0040455 & 0.000407458 \\
400 & -0.0075882 & 0.000295999 \\
450 & -0.0873501 & 0.005812691 \\
500 & -0.0143933 & 0.000737528 \\
550 & -0.0227223 & 0.001333157 \\
600 & -0.0125914 & 0.000557827 \\
650 & -0.0140123 & 0.000666346 \\
700 & -0.0115637 & 0.000350065 \\
750 & -0.0044663 & 0.000272965 \\
800 & -0.0082027 & 0.000439174 \\
850 & -0.0063556 & 0.000348959 \\
900 & -0.0153325 & 0.000575689 \\
950 & -0.0041115 & 0.000617574 \\
1,000 & 0 & 0 \\
\hline
\end{tabular}

or

$$
w_{0}(z)=w_{0}^{(\mathrm{I})}(z)+\frac{\mu}{\rho} w_{0}^{(\mathrm{II})}(z)
$$

The numerical values of $w_{0}^{(\mathrm{I})}(z)$ and $w_{0}^{(\mathrm{II})}(z)$ are compiled in Table 4.

Thus it is seen that both upwelling and sinking, or the vertical flows at the Equator consist of two parts, that is, the term $w_{0}^{(\mathrm{I})}(z)$ due to mass distribution and wind stress on the sea surfaces and the second part proportional to $\frac{\mu}{\rho}$, or depending on the magnitude of eddy viscosity. This fact means that the intensity of upwelling and sinking at the equator primarily depends upon the magnitude of $\frac{\mu}{\rho}$, since there are, in equatorial regions, no large annual variation in mass distribution and wind stress at the surface of the sea.

The vertical flow $w_{0}(z)$ was computed for $\frac{\mu}{\rho}=5,10,15.02748,18.09243,50,100,200$ and 500 c.g.s. The value $\frac{\mu}{\rho}=18.09243$ was chosen in place of 20 , because this value makes $w_{40}=0$.

Table 5. Intensity of Vertical Flow, $w_{0}(z)$ in $10^{-3} \mathrm{~cm} / \mathrm{sec}$, or Upwelling (negative sign) and Sinking (positive sign) at the Equator for Several Different Values of $\frac{\mu}{\rho}$.

\begin{tabular}{|c|c|c|c|c|c|c|c|c|c|}
\hline $\begin{array}{l}\text { depth } z \\
\text { (in meters) }\end{array}$ & $\begin{array}{c}\frac{\mu}{\rho} \\
\stackrel{\rho}{=}\end{array}$ & $\begin{array}{l}\frac{\mu}{\rho} \\
\stackrel{\rho}{=} 5\end{array}$ & $\begin{array}{l}\frac{\mu}{\rho} \\
=10\end{array}$ & $\begin{array}{c}\frac{\mu}{\rho} \\
=15.02749\end{array}$ & $\begin{aligned} & \frac{\mu}{\rho} \\
= & 18.09\end{aligned}$ & $\begin{array}{l}\frac{\mu}{\rho} \\
=50\end{array}$ & $\begin{array}{l}\frac{\mu}{\rho} \\
=100\end{array}$ & $\begin{aligned} & \frac{\mu}{\rho} \\
= & 200\end{aligned}$ & $\begin{array}{l}\frac{\mu}{\rho} \\
=500\end{array}$ \\
\hline 0 & 0 & 0 & 0 & 0 & 0 & 0 & 0 & 0 & 0 \\
\hline 50 & 1.6 & 10.0 & 3.7 & -2.7 & -5.7 & -47.1 & -110.5 & -237.3 & -617.8 \\
\hline 100 & 2.0 & -15.0 & 10.1 & 5.2 & -2.2 & -29.0 & -77.9 & -175.6 & -468.9 \\
\hline 150 & -6.0 & -6.4 & -6.8 & -7.2 & -7.5 & -10.0 & -14.0 & -22.1 & -34.0 \\
\hline 200 & -1.6 & -1.7 & -1.9 & -2.0 & -2.1 & -2.9 & -4.2 & -6.8 & -11.5 \\
\hline 250 & 0.1 & -1.2 & -2.6 & -4.0 & -4.8 & -13.5 & -23.0 & -54.2 & -135.7 \\
\hline 300 & 0.1 & 0.4 & -0.9 & -1.5 & -1.8 & -5.2 & -10.6 & -21.3 & -53.4 \\
\hline 350 & -4.0 & -2.0 & - $\quad 0$ & 2.1 & 3.3 & 16.3 & 36.7 & 77.4 & 199.7 \\
\hline 400 & -7.6 & -6.1 & -4.6 & -3.1 & -2.2 & 7.2 & 22.0 & 51.6 & 140.4 \\
\hline 450 & -8.7 & -58.3 & -29.2 & 0 & 17.8 & 203.3 & 493.1 & 1075.2 & 2819.0 \\
\hline 500 & -14.4 & -10.7 & -7.0 & -3.3 & -1.1 & 22.5 & 59.4 & 133.1 & 354.4 \\
\hline 550 & -22.7 & -16.1 & -9.3 & -2.7 & 1.4 & 43.9 & 110.6 & 243.9 & 643.9 \\
\hline 600 & -12.6 & -9.8 & -7.0 & -4.2 & -2.5 & 15.3 & 43.2 & 99.0 & 266.3 \\
\hline 650 & -14.0 & -10.7 & -7.3 & -4.0 & -2.0 & 19.3 & 52.6 & 119.3 & 319.2 \\
\hline 700 & -11.6 & -9.8 & -8.1 & -6.3 & -5.2 & 5.9 & 23.4 & 58.4 & 163.5 \\
\hline 750 & -4.5 & -3.1 & -1.7 & -0.4 & 0.5 & 9.2 & 22.8 & 50.1 & 132.0 \\
\hline 800 & -8.2 & -6.0 & -3.8 & -1.6 & -0.2 & 13.8 & 35.7 & 79.6 & 211.4 \\
\hline 850 & -6.4 & -4.6 & -2.6 & -1.1 & 0 & 11.1 & 28.5 & 63.4 & 168.1 \\
\hline 900 & -5.3 & -12.5 & -9.6 & -6.7 & -4.9 & 13.5 & 42.2 & 99.8 & 272.5 \\
\hline 950 & -4.1 & -1.0 & -2.1 & 5.2 & -0.8 & 26.8 & 57.6 & 119.4 & 304.7 \\
\hline 1,000 & 0 & 0 & 0 & 0 & 0 & 0 & 0 & 0 & 0 \\
\hline
\end{tabular}


The result is compiled in Table 5 . The discrepancies in the order of magnitudes between those values and those of Table 2 of previous paper (HIDAKA, 1965) will be due mostly to the uncertainity of numerical differentiations.

\section{Discussion on the result}

Table 5 gives the result of final computation, or the vertical flow in $\mathrm{cm} / \mathrm{sec}$, giving the intensity of upwelling, (negative sign) and sinking (positive sign) for several different values of $\frac{\mu}{\rho}$. When $\frac{\mu}{\rho}$ is small $\left(0<\frac{\mu}{\rho}<20\right)$, there is upwelling in most depths except at shallow layers just below the surface. The magnitude of upwelling is between $10^{-3}$ and $10^{-2} \mathrm{~cm} / \mathrm{sec}$. For $\frac{\mu}{\rho}=18.09242$ which makes $w_{40}=0$, the equatorial water upwells in most layers except there is a rather intense sinking around $450 \mathrm{~m}$ level $(0.0178 \mathrm{~cm} / \mathrm{sec})$. (Fig. 2) To remove this intermediate sinking, we can assume $\frac{\mu}{\rho}=15.02748$ for which $w_{0}(z)$ vanishes at $450 \mathrm{~m}$ level. (Table 5 and Fig. 1)

For larger values of $\frac{\mu}{\rho}$, upwelling is confined in the layers shallower than $300 \mathrm{~m}$, whereas sinking predominates in deeper layers down to the reference surface $(h=1,000 \mathrm{~m})$. The intensity of both upwelling and sinking tends to asymptotic vertical distribution, expressed by the formula:

$$
w_{0}(z)=\frac{\mu}{\rho} w_{0}^{(\mathrm{II})}(z),
$$

when $\frac{\mu}{\rho}$ is large. For $\frac{\mu}{\rho}=50$ c.g.s., the upwelling has a maximum velocity $w_{0}(z)=-0.0471$ $\mathrm{cm} / \mathrm{sec}$. at $50 \mathrm{~m}$, and sinking a maximum $w_{0}(z)=0.2033 \mathrm{~cm} / \mathrm{sec}$. at $450 \mathrm{~m}$. (Fig. 3) For $\frac{\mu}{\rho}=100,200$ and 500 c.g.s., maximum values of upwelling exist at $50 \mathrm{~m}$ layer, having values of $0.1105,0.273$ and $0.6178 \mathrm{~cm} / \mathrm{sec}$. upwards, while the maximum values of sinking are $0.4931,1.0752$ and $2.8190 \mathrm{~cm} / \mathrm{sec}$. respectively at $450 \mathrm{~m}$ level.

There will be questions on the real existence of these large values of sinking at 450 meter level, because they are quite unreasonable magnitudes for a vertical motion of water even if we permit the particular circumstances which may prevail at the equator. This result may suggest that there cannot be large eddy viscosity in equatorial regions.

In a previous paper by the author (HIDAKA,

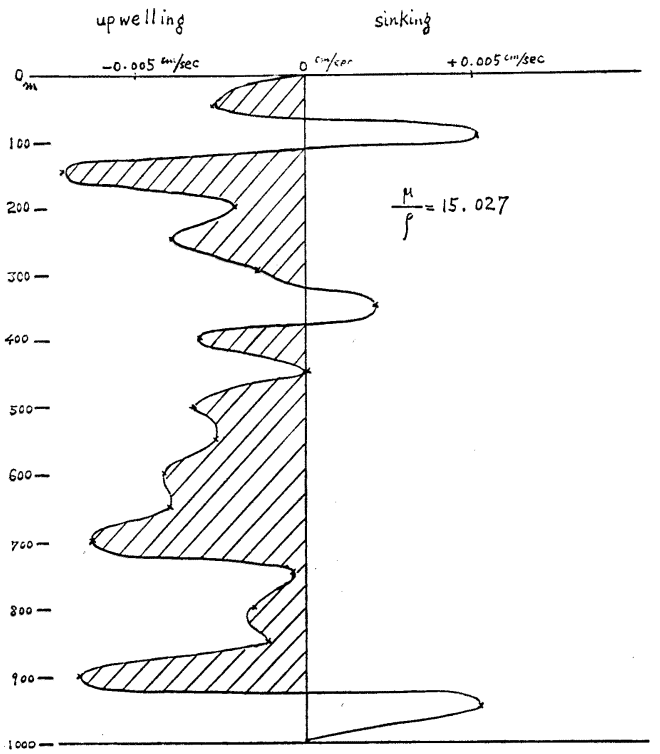

Fig. 1. Computed upwelling (shaded area) and sinking for $\frac{\mu}{\rho}=15.027$.

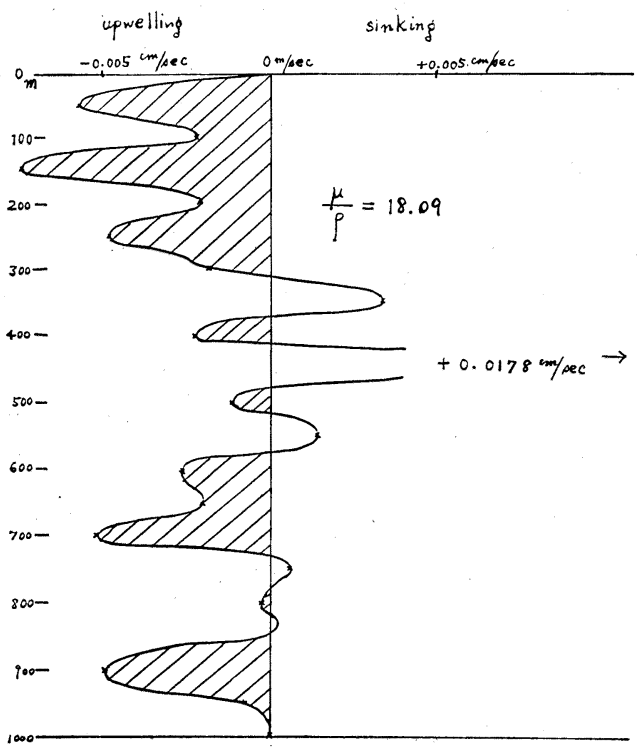

Fig. 2. Computed upwelling (shaded area) and sinking for $\frac{\mu}{\rho}=18.09$. 


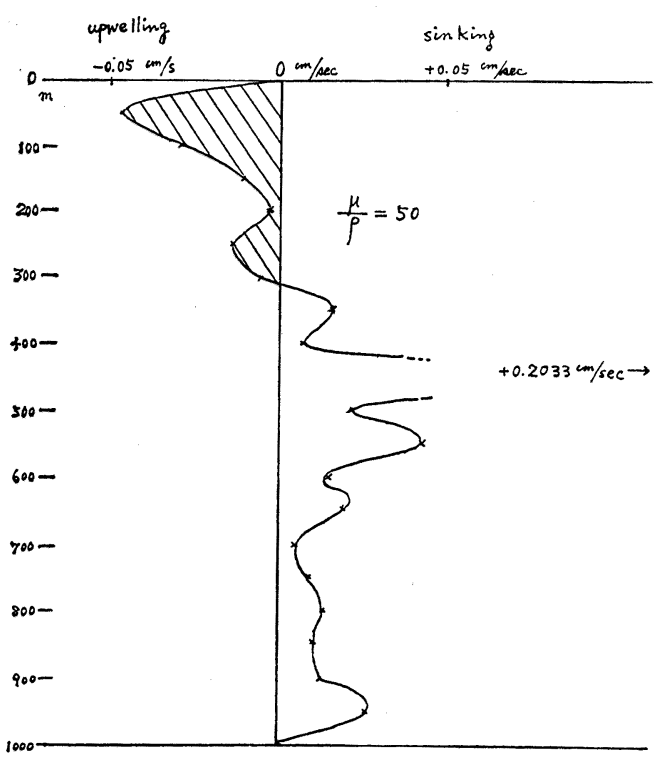

Fig. 3. Computed upwelling (shaded area) and sinking for $\frac{\mu}{\rho}=50$.

1965), an anticipation of an intense upwelling at the equator is suggested. The same applies in the present consideration. It should be remembered, however, that the deeper part of Knauss's composite vertical profile of the Equatorial Undercurrent is less trustable, because of the slow horizontal flows and the difficulty in directly measuring them. Therefore, no guarantee will be given for a real existence of such a big vertical flows.

Professor Kozo YosHIDA, University of Tokyo, does not seem to be quite convinced with my numerical results. To make a rough check of the results, he suggests possible computations of vertical velocities from the two equations not used in the present paper: One from the equation of heat conservation and the other from the equation of continuity. Yoshida's preliminary calculation appears to show certain similarity between my dynamical results and his from the thermal equation.

\section{Summary}

The intensity of vertical flow at the equator was computed from the hydrodynamical equations by using actual observations of zonal component of the Equatorial Undercurrent and as many terms in the hydrodynamical equations and observed elements as possible. It was concluded that the equatorial vertical flow depends largely on $\frac{\mu}{\rho}$, to a larger value of which $\left(\frac{\mu}{\rho}>50\right.$ c.g.s. $)$ there predominates upwelling in the layers shallower than 300 meters and sinking predominates in deeper layers. The magnitudes of these vertical flows are of the order of $10^{-3}$ to $10^{-2} \mathrm{~cm} / \mathrm{sec}$, or larger, thus suggesting intense upwelling and sinking at the Equator.

\section{Acknowledgements}

This work was started while author was visiting the University of Chicago in the Department of Geophysical Sciences April through June 1965. He is much obliged to Professor George W. PlatzMan for his kind advices. Afterward it was completed during the author's stay in the Lamont Geological Observatory, Columbia University in January and February 1966. He must thank to Dr. Takashi ICHIYE of the Observatory, who provided the author with many valuable suggestions on this research. He is also much indebted to Professor Kozo YosHIDA, Geophysical Institute, University of Tokyo, who has kindly checked the result before printing.

For solving $20 \times 20$ matrices, the author is much indebted to Dr. Toshihiko Teramoto, Assistant Professor, Ocean Research Institute, University of Tokyo, and to Miss Masuko WAKABAYASHI who assisted the author in electronic computations.

\section{References}

ARTHUR, R. S. (1960): A Review of the Calculation of Ocean Currents at the Equator. Deep-sea Research, 6, 287-297.

CROMWELL, Tounend, R. B. MONTGOMERY and STROUP (1954): Equatorial Undercurrent in the Pacific Ocean Revealed by New Method. Science, 119, 648-649.

HidAKA, Koji (1962): Non-linear Theory of an Equatorial Flow, with Special Application to the Cromwell Current. Journal of Oceanographic Society of Japan, 20th Anniversary Volume, 223-241.

HidAKA, Koji (1963): Non-linear Computation of 
the Equatorial Current System of the Pacific (1) Computation of Epuatorial Velocity. Journal of Oceanographic Society of Japan, 19: 121-135.

HIDAKA, Koji (1965): Evidences of an Intense Upwelling at the Equator. La Mer; Bulletin de la Société franco-japonaise d'océanographie, 3, 1-8. KNaUss, John A. (1960): Measurements of the Cromwell Current. Deep-sea Research, 6, 263-386.

\section{赤道湧昇流の非線型計算}

日高孝次

要旨 赤道に於ける湧昇流や沈降流を流体力学の運動方 程式に於ける非線型項を省略しないで計算する方法を考 えてみた. 東方に $x$ を, 北方に $y$ を, 下方に $z$ をそれ ぞれ正に採り, 問題を簡単にするために, 海面が西から 東に下降するための東西王力傾度は勿論省略出来ない が, 速度成分の東西傾度は省略出来ると仮定して方程式 を簡略にし，連続の条件及び $\varphi=0$ という条件に依って だけの非線型二次微分方程式を導びき，これに各層の圧 力傾度の他に赤道潜流の実際の観測值や風の応力の平均
值等を代入して正弦函数の級数として鉛直流を計算し得 た. その結果は $w(z)=w^{\mathrm{I}}(z) \frac{\mu}{\rho} w^{\mathrm{II}}(z)$ の如き $\frac{\mu}{\rho}$ の一 次式で表されるが，刎論 $\frac{\mu}{\rho}$ の如何なる值に対しても実 際を表わすとは考えられない. 尚圧力傾度等（圧面の傾 度), 風の応力, 潜流の東西成分等が同時に同経度が測 られたわけではないから結果は単に計算の可能性を示す のみでこれに依って実際現象を説明する段階に未だ達 していない. 